\title{
Erratum to: Dujardinascaris gigantea sp. n. (Nematoda: Ascaridida) from the critically endangered crocodile Alligator sinensis Fauvel (Reptilia: Crocodylia)
}

\author{
Jin-Hong Zhao • Liang Li • Yan-Ning Guo • \\ Lu-Ping Zhang
}

Published online: 11 January 2015

(C) Springer-Verlag Berlin Heidelberg 2015

\section{Erratum to: Parasitology Research \\ DOI 10.1007/s00436-014-3980-z}

The authors of the article "Dujardinascaris gigantea sp. n. (Nematoda: Ascaridida) from the critically endangered crocodile Alligator sinensis Fauvel (Reptilia: Crocodylia)“" published in Parasitology Research (2014) DOI 10.1007/s00436014-3980-z would like to amend the list of authors by the addition of Jinhong Zhao, who also made important contributions to this work. As a result of this, J. Zhao will be included in the author list as follows: Jin-Hong Zhao ${ }^{\mathrm{a}, \mathrm{c}, 1}$, Liang $\mathrm{Li}^{\mathrm{b},{ }^{*}, 1}$, Yan-Ning Guo ${ }^{\mathrm{b}}$, Lu-Ping Zhang ${ }^{\mathrm{b}}$

Jin-Hong Zhao and Liang Li contributed equally to this work.

The online version of the original article can be found at http://dx.doi.org/ 10.1007/s00436-014-3980-z.

J.-H. Zhao

College of Life Science, Anhui Normal University, 241000 Wuhu, Anhui Province, People's Republic of China

L. Li $(\varangle) \cdot$ Y.-N. Guo $\cdot$ L.-P. Zhang

Key Laboratory of Animal Physiology, Biochemistry and Molecular Biology of Hebei Province, College of Life Science, Hebei Normal University, 050024 Shijiazhuang, Hebei Province, People's Republic of China

e-mail: liangliangex369@126.com

J.-H. Zhao

Department of Medical Parasitology, Wannan Medical University,

241000 Wuhu, Anhui Province, People's Republic of China 